\title{
Airglow and other F-layer variations in the Indian sector during the geomagnetic storm of February 5-7, 2000
}

\author{
G. K. Mukherjee \\ Indian Institute of Geomagnetism, New Panvel (W), Navi Mumbai 410 206, India \\ (Received February 23, 2005; Revised November 18, 2005; Accepted November 19, 2005; Online published May 12, 2006)
}

\begin{abstract}
A CCD based all-sky imaging system was used to monitor various nightglow emissions (OI 630-nm, OI 557.7$\mathrm{nm}, \mathrm{OI} 777.4-\mathrm{nm}, \mathrm{Na}(589.3-\mathrm{nm})$ and hydroxyl $(\mathrm{OH})$ airglow) at a low latitude station, Kolhapur $\left(16.8^{\circ} \mathrm{N}, 74.2^{\circ} \mathrm{E}\right.$, dip lat $10.6^{\circ} \mathrm{N}$ ) in India to study the characteristics of night airglow variations observed during the period of a moderate/weak geomagnetic storm with SSC (Storm Sudden Commencement) commencing at 15:42 UT (21:12 IST (Indian Standard Time $=$ UT +5.5 hrs)) on February 5, 2000. The images on the night of February 6 show the development of strong ionization anomaly (EIA) with bright intensity regions in OI 630-nm and the signature of rising bubbles with very low intensity. Though the signature of ionospheric plasma bubbles were not observed on the night of February 7, the OI 630-nm images showed the presence of large scale enhanced airglow moving to the southeast direction. The speed was significantly fast $(\sim 300 \mathrm{~m} / \mathrm{s})$. There were bright intensity regions also observed in OI 557.7-nm airglow, but no intensity enhancement was seen in other mesospheric emissions $(\mathrm{Na}(589.3-\mathrm{nm})$ and hydroxyl $(\mathrm{OH})$ airglow ) during this magnetic disturbance. The ionosonde observations at the nearby station, Visakhapatnam (lat. $17.67^{\circ} \mathrm{N}$, long. $83.32^{\circ} \mathrm{E}$ ) also showed enhancement in electron density parameter $\left((\mathrm{foF} 2)^{2}\right)$ at the station on each night compared to the night of February 4-5 (quiet day) around the same time interval maximizing around 23:00 IST on the night of February 7. The Total Electron Content (TEC) fluctuations obtained from GPS phase delays between two L-band signals $(L 1=1575 \mathrm{MHz}$ and $L 2=1227$ $\mathrm{MHz}$ ) showed no enhancement at night at four mid latitude stations in Japan. However, noontime TEC values were enhanced on February 6 and 7 with maximum intensity occurring on February 7. It is inferred that enhanced storm time effects in the ionosphere were mainly confined to the low latitude region, the effects were subdued in the mid latitude stations.
\end{abstract}

Key words: Ionosphere, Equatorial ionosphere, Ionospheric irregularities, Electric fields and currents.

\section{Introduction}

The ground based measurements of various F-region and mesospheric nightglow emissions (OI 630-nm, 557.7$\mathrm{nm}, 777.4-\mathrm{nm}$, Na $(589.3 \mathrm{~nm})$ and hydroxyl $(\mathrm{OH})$ airglow) provide important information on the response of the ionosphere-thermosphere during the different phases of a geomagnetic storm. The ionospheric effect of the magnetic storms including the OI 630-nm emissions of the neutral atmosphere perturbations during Solar Cycle Maximum at equinox has been presented by Fesen et al. (1989). Several researchers have brought out the salient features of Fregion storm effects by multi spectral optical observations at equatorial and low latitude stations. Optical and particle measurements made from the ISIS-II spacecraft during August 1972 geomagnetic storm have been reported by Shepherd et al. (1976). They found strong enhancement of thermally produced OI 630-nm emission due to plasma heating over two different regions in the magnetosphere during a major storm. Danilov and Morozova (1985) reported that the observed F-region effects varied depending upon the latitude, longitude, local time and the time of elapse from

Copyright (c) The Society of Geomagnetism and Earth, Planetary and Space Sciences (SGEPSS); The Seismological Society of Japan; The Volcanological Society of Japan; The Geodetic Society of Japan; The Japanese Society for Planetary Sciences; TERRAPUB. the commencement of the storm. In general, there is general agreement that during magnetic disturbances the critical frequency of the F2 layer, foF2 increases (positive effect) at the low latitude regions (Rajaram et al., 1971) and decreases (negative effect) at the mid latitude regions. However, there are considerable variations from one magnetic storm to other so that the most general behavior as observed above is often not followed (Danilov and Morozova, 1985; Kane, 1981).

F-region night airglow emission OI 557.7-nm and 630$\mathrm{nm}$ resulting from dissociative recombination of $\mathrm{O}_{2}^{+}$ions and electrons and at OI777.4-nm resulting from radiative recombination of $\mathrm{O}^{+}$and electrons can be used to sense remotely the storm time response of the ionospheric layers. The $\mathrm{O}_{2}^{+}$is produced from charge transfer of $\mathrm{O}^{+}$with $\mathrm{O}_{2}$ and observed OI $630-\mathrm{nm}$ emission is proportional to the column integral $\left(\int n\left(\mathrm{O}^{+}\right) n\left(\mathrm{O}_{2}\right) d s\right)$ of the product of $\mathrm{O}^{+}$ and $\mathrm{O}_{2}$ concentration. Thereby this emission is strongly dependent on height changes associated with the bottom side of the F-layer and directly proportional to the F-layer electron density. However, the major portion of OI 557.7-nm emission comes from the recombination of oxygen atoms in the mesopause region $(80-100 \mathrm{~km})$. There is a general agreement that the OI 557.7-nm emission is excited by the so-called two-step energy transfer process $\mathrm{O}+\mathrm{O}+\mathrm{M} \rightarrow$ 
Table 1. Filter details and exposure times for the All-sky Imager.

\begin{tabular}{lcccc}
\hline \multicolumn{1}{c}{ Wavelength } & Diameter of the filters (inch) & Band width (nm) & Transmission $(\%)$ & Integration time (sec) \\
\hline OI $557.7 \mathrm{~nm}$ & 4 & 1.0 & 65 & 60 \\
OH $^{*} 720-910 \mathrm{~nm}$ & 4 & 190 & 65 & 15 \\
OI $630 \mathrm{~nm}$ & 4 & 1.0 & 65 & 60 \\
$589.3 \mathrm{~nm}$ & 4 & 1.0 & 65 & 60 \\
OI $777.46 \mathrm{~nm}$ & 4 & 1.0 & 65 & 60 \\
$530 \mathrm{~nm}$ & 4 & 1.0 & 65 & 60 \\
\hline
\end{tabular}

*With a notch at $865 \mathrm{~nm}$ to suppress $\mathrm{O}_{2}(0,1)$ emission.

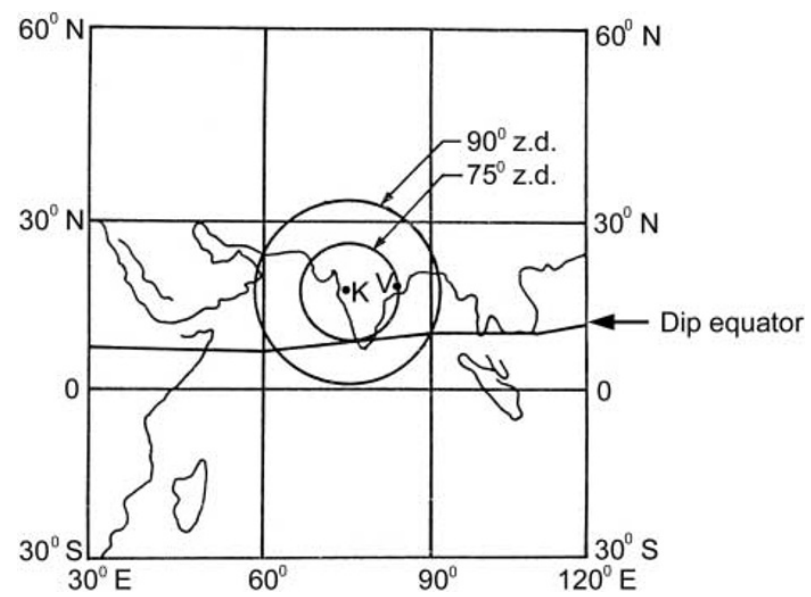

Fig. 1. Field of view at $75^{\circ}$ and $90^{\circ}$ zenith angles at $300 \mathrm{~km}$ for the all-sky imager at Kolhapur.

$\mathrm{O}_{2}^{*}+\mathrm{M}, \mathrm{O}_{2}^{*}+\mathrm{O} \rightarrow \mathrm{O}\left({ }^{1} \mathrm{~S}\right)+\mathrm{O}_{2}$. Several researchers have reported the observations of OI 630-nm emissions during magnetic storms at low latitude regions (Barbier, 1962; Saito, 1973; Sahai et al., 1988, 1990). Some of them have found unusual enhancement of the OI 630-nm emission (Sahai et al., 2001; Saito; 1973; Kiyama et al., 1996) during different phases of magnetic storms at low and mid-latitude stations. Sahai et al. (1990) presented the first simultaneous ground-based measurements of the OI 777.4-nm, 630-nm and 557.7-nm emissions from Cachoeira Paulista $\left(22.7^{\circ} \mathrm{S}\right.$, $\left.45.0^{\circ} \mathrm{W}\right)$, Brazil, a low latitude station and from Fortaleza $\left(3.9^{\circ} \mathrm{S}, 38.4^{\circ} \mathrm{W}\right)$, Brazil, an equatorial station, during magnetic disturbances. They found the dynamic variations in the $\mathrm{F}$ region ionospheric parameters were well correlated with the non-diurnal variations observed in the atomic oxygen airglow emissions at both equatorial and low latitudes. We report here the simultaneous measurements of the allsky distribution of OI 630-nm, OI 557.7-nm, OI 777.4-nm, $\mathrm{Na}(589.3-\mathrm{nm})$ and hydroxyl $(\mathrm{OH})$ airglow emissions in order to study the relationship between F-region airglow and mesospheric emissions from Kolhapur, a low latitude station in India during the magnetic storm of February 5-7, 2000 .

\section{Geometry of Observations}

Figure 1 shows the location of the airglow observing station, Kolhapur along with station, Visakhapatnam $\left(17.67^{\circ} \mathrm{N}, 83.32^{\circ} \mathrm{E}\right)$ whose ionosonde data have been used in the present study with respect to geographic coordinates. The two circles indicate the coverage of the all-sky imaging system for zenith distances $75^{\circ}$ and $90^{\circ}$ for an emission height of $300 \mathrm{~km}$.

\section{Observations}

The all-sky imager that we used for observation was developed in collaboration with Boston University, U.S. This has six filters on a wheel, a fish-eye lens that has a field of view of $180^{\circ}$ and an intensified cooled CCD camera with $384 \times 256$ pixels (Baumgardner and Karandanis, 1984; Mukherjee et al., 1998; Mukherjee, 2003). The details about the filters and the exposure time are given in Table 1. The various emission lines originating at different mesospheric and ionospheric heights can be studied almost simultaneously with the help of this system. The nightglow observation was carried out from Kolhapur (Fig. 1) in India and the observation period was during the nights between February 4-7, 2000. A geomagnetic storm was in progress on the night of February 5 with a sudden commencement at 15:42 UT (21:12 IST) and the storm lasted up to 03:00 UT (08:30 IST) in the morning on February 8, the minimum Dst value was reached as $-44 \mathrm{nT}$ on February 7, 2000 around 03:00 UT (08:30 IST). The average daily decimetric solar flux indices $(\mathrm{F} 10.7 \mathrm{~cm})$ were varying from 163 to 177 (units of $10^{-22} \mathrm{w} \mathrm{m}^{-2}$ ) during the period.

Figure 2 shows the sequence of OI 630-nm images observed on the night of February 5 at 23:02-23:53 IST and February 6 at 23:12-23:51 IST. For comparison, the images on the night of February 4 (Quiet day) at 22:08-22:53 IST were also depicted in the figure. The images were flat fielded after subtracting their background values. The images depict the optical signatures of north-south aligned band structures of ionospheric plasma bubbles. Several such plasma depletions marked by arrows could be seen in the images. These structures move from west to east in the sky. At 23:10 IST on February 5, a set of four bubbles is seen in the western part of the sky, the westward tilt of the structures is about $20^{\circ}$. Simultaneously the tilt of the bubble increases with the progress of time and it is about $45^{\circ}$ around midnight at 23:53 IST. The westward tilt of the structures have been explained as due to the influence of eastward plasma drifts that decrease with altitude above F2 peak and the shear resulting from an latitudinal decrease in zonal wind. This type of mechanism was proposed by An- 

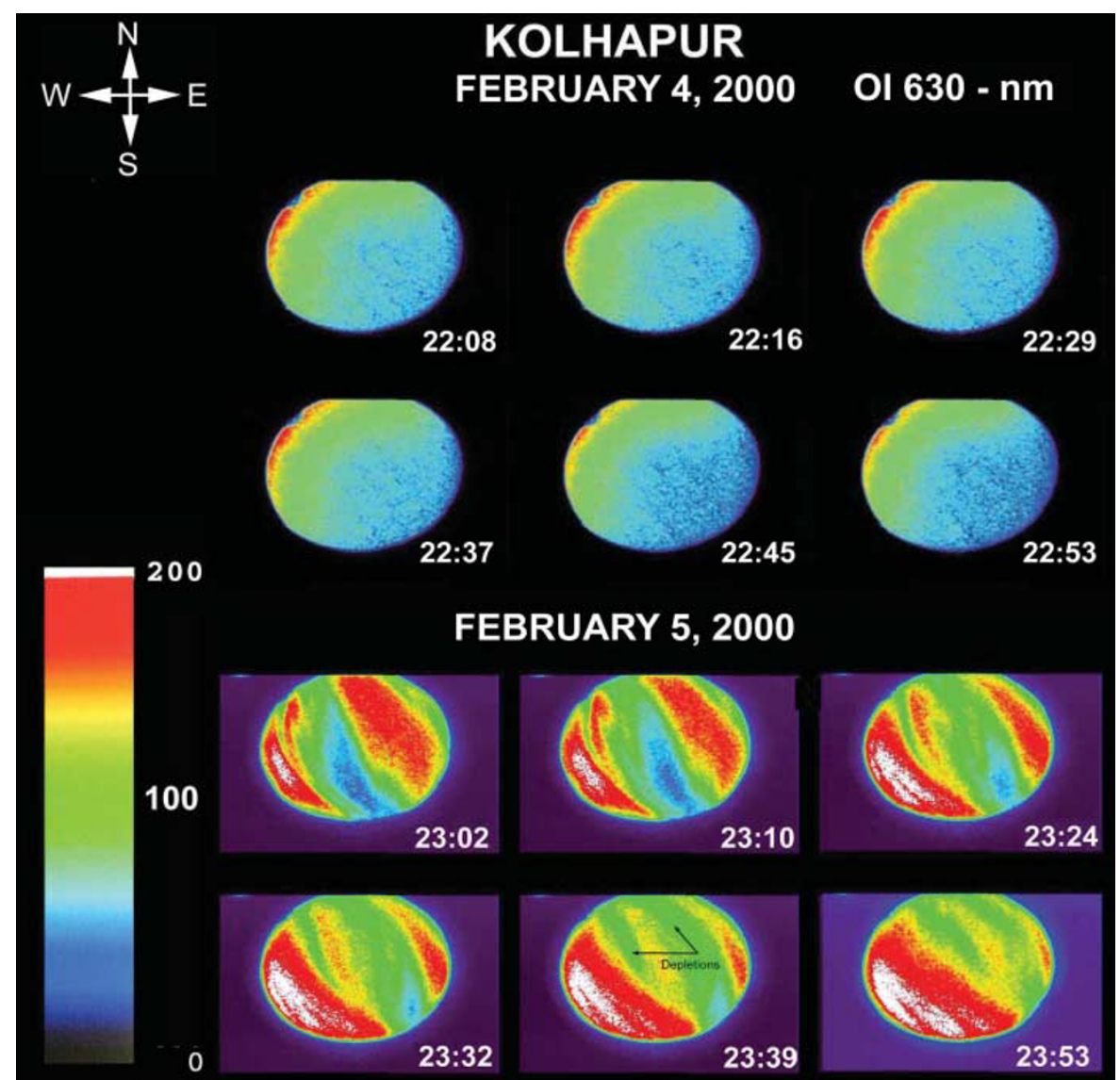

FEBRUARY 5, 2000

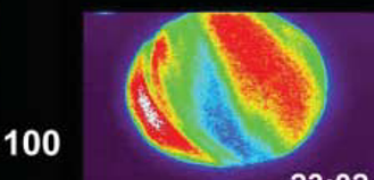

23:02
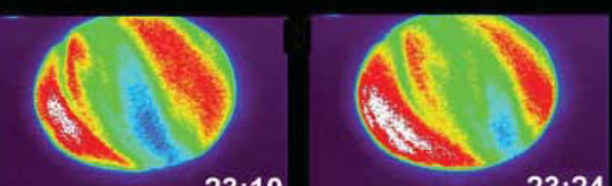

23:10

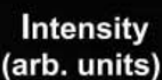

0
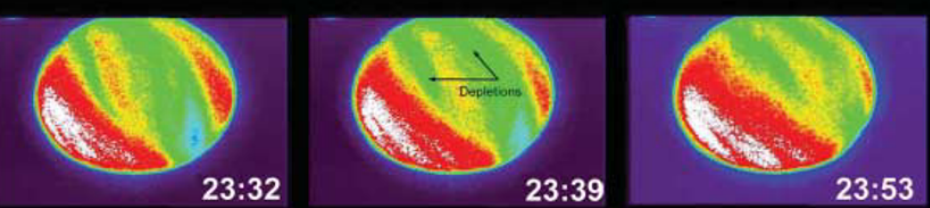

(arb. units)

FEBRUARY 6, 2000
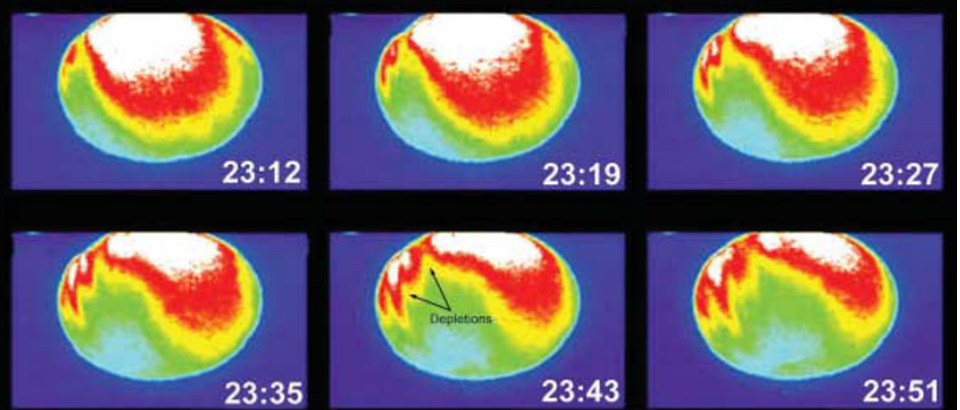

\section{IST (HRS)}

Fig. 2. All-sky images ( $180^{\circ}$ field of view) of OI 630-nm emission observed at Kolhapur during the night of February 4, February 5 and February 6 , 2000 .

derson and Mendillo (1983) and such westward tilts in depletions have been observed earlier by ground based imaging systems (Weber et al., 1980; Mendillo and Tyler, 1983) and also by incoherent scatter radar (Woodman and LaHoz, 1976; Tsunoda, 1980) and by in situ probes (Mclure et al., 1977). The images on the night of February 6 show the enhancement in OI 630-nm intensity with the development of strong ionization anomaly (EIA) and the signature of rising ionospheric plasma bubbles with very low intensity. The small-scale irregularities (1 meter to kilometer size) present within the bubbles gave rise to strong VHF scintillations recorded at the station, which has been discussed in the later section.
We take the equatorial cross section of several OI 630-nm images and calculate their intensity at each pixel from east to west direction using IDL software. In Fig. 3 we depict the OI 630-nm intensity values on the night of February 5, 2000 at Kolhapur as a function of their pixel number (East-west) when ionospheric plasma bubbles were observed. The figure shows several dips in intensity values shown by arrows adjacent to high intensity regions. We would be studying here how the size (east-west width in $\mathrm{km}$ ) of the bubbles and the depth (the difference between maxima and minima in intensity values as a percentage of maximum) of depletions observed at Kolhapur fluctuate as the time progresses. From the plots, we determine the east-west width $(\mathrm{km})$ and 
KOLHAPUR

FEBRUARY 5, 2000

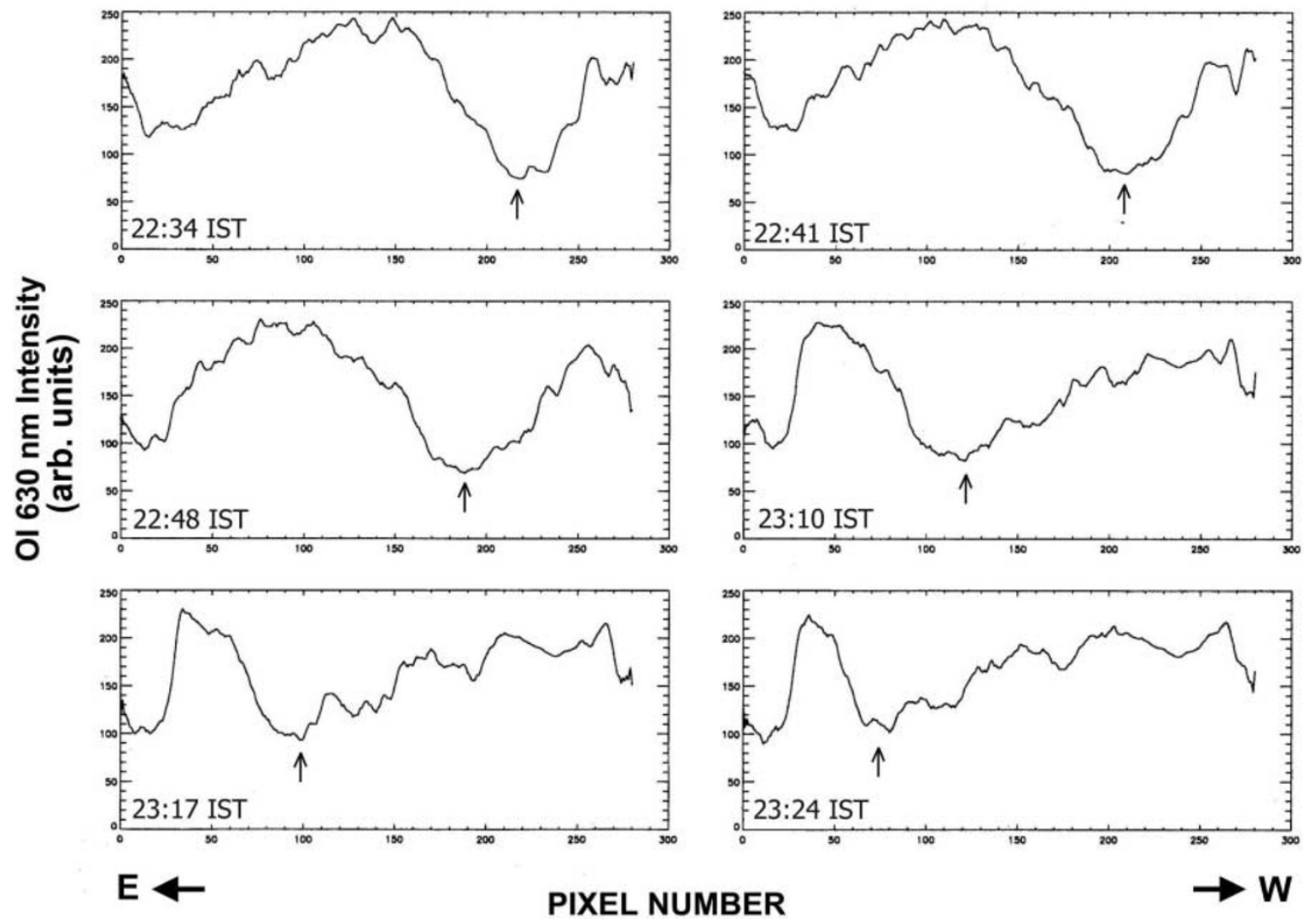

Fig. 3. Intensity plot of OI 630-nm showing the widths and depths of ionospheric plasma depletions at 22:34-23:24 IST on the night of February 5, 2000 as a function of the pixel number in east west direction at Kolhapur.

depth $(\%)$ of the plasma depletions at 22:34, 22:41, 22:48 IST and they were found to be $(350 \mathrm{~km}, 64 \%),(400 \mathrm{~km}$, $66 \%),(400 \mathrm{~km}, 65 \%)$ respectively. It is clear that bright region also moves from west towards the east along with the depletion region. The western wall of the depletions start showing small-scale wavy structures within the depletions at 23:17 and 23:24 IST.

Figure 4(a) shows the sequences of all-sky images of OI 630-nm emission from 21:19 to 23:53 IST observed on the night of February 7, 2000 at Kolhapur. The emission intensity was relatively low until 22:27 IST, after that it was remarkably enhanced. At 22:35 IST, the northern edge of the image started showing enhancement and enhanced area extended fast $(300 \mathrm{~m} / \mathrm{s})$ to the southward direction covering most of the field of view at 23:53 IST. It is very interesting to make a simultaneous measurement of the all-sky distribution of the OI 557.7-nm, OI 777.4-nm, Na (589.3$\mathrm{nm})$ and hydroxyl $(\mathrm{OH})$ airglow originating at mesospheric height to study the relationship and coupling between MLT $(75-130 \mathrm{~km})$ and $\mathrm{F}$ region during magnetic disturbance. It was clearly observed as shown in Fig. 4(b) that OI 557.7$\mathrm{nm}$ emissions were also enhanced during the period of magnetic disturbance. The enhancement of OI 630-nm and OI $557.7-\mathrm{nm}$ intensity was two and one order more in magnitude compared to the background intensity. The intensity of other emissions (OI 777.4-nm, Na (589.3-nm) and hydroxyl $(\mathrm{OH})$ airglow) remained unaffected during the night. In or- der to save space only the hydroxyl $(\mathrm{OH})$ images are shown in Fig. 4(c), others were not depicted. OI 777.4-nm emission is very weak in low latitude region and is dependent on F region peak electron density, $N_{\max }$ and independent of height of the layer. If perturbations in F-region during magnetic storms do not change $N_{\max }$ significantly, then the intensity OI 777.4-nm emission remains unaffected.

Sahai et al. (1990) reported the first simultaneous ground-based measurements of the OI 777.4-nm, 630-nm and 557.7-nm emissions from Cachoeira Paulista $\left(22.7^{\circ} \mathrm{S}\right.$, $\left.45.0^{\circ} \mathrm{W}\right),(\mathrm{CP})$ in Brazil, a low latitude station and from Fortaleza $\left(3.9^{\circ} \mathrm{S}, 38.4^{\circ} \mathrm{W}\right)(\mathrm{FTZ})$ in Brazil, an equatorial station, during magnetic disturbance. The observations of the OI 777.4-nm and 630-nm emissions on the disturbed night of 25-26 August at FTZ do not show any enhancement when a large enhancement in these emissions at $\mathrm{CP}$ is evident. On the basis of theoretical results, Tinsley (1979) reported that energetic neutral atom flux might be stronger at low and mid-latitudes and weaker at equatorial latitudes during the main phase of the storm. Our present observations do not show any evidence of enhancement of the OI 777.4-nm emission. It is reported that during magnetic storms, the OI 777.4-nm emission follows (foF2) ${ }^{4}$ (Moore and Weber, 1981) indicating that radiative recombination is the main excitation mechanism and no enhancements were observed when there was evidence of energetic particle precipitation from ring current. Using the data obtained in 


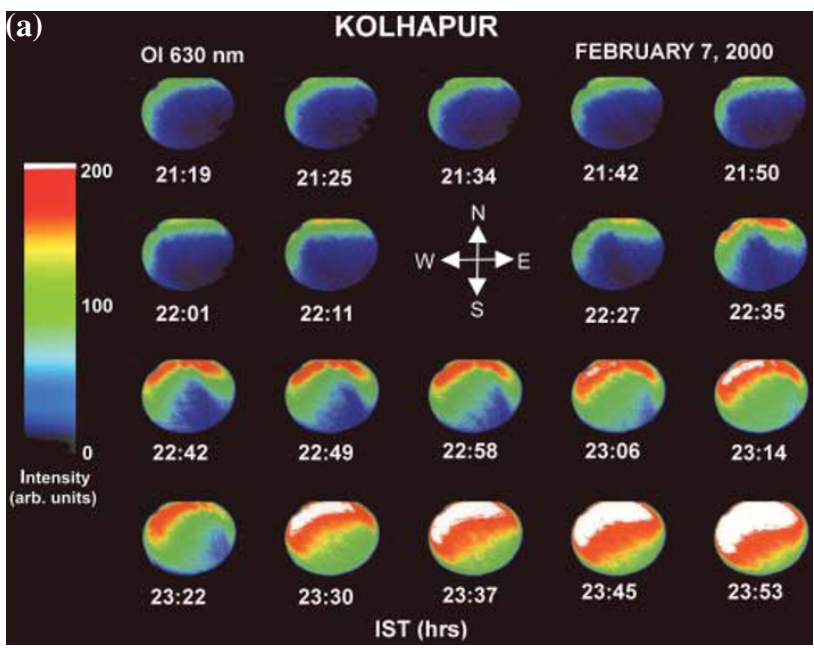

Fig. 4(a). All-sky images ( $180^{\circ}$ field of view) of OI $630-n m$ on the night of February 7, 2000 at Kolhapur showing severe enhancement in OI 630-nm night airglow in the northern sky from 22:11 IST onwards maximizing at 23:53 IST.

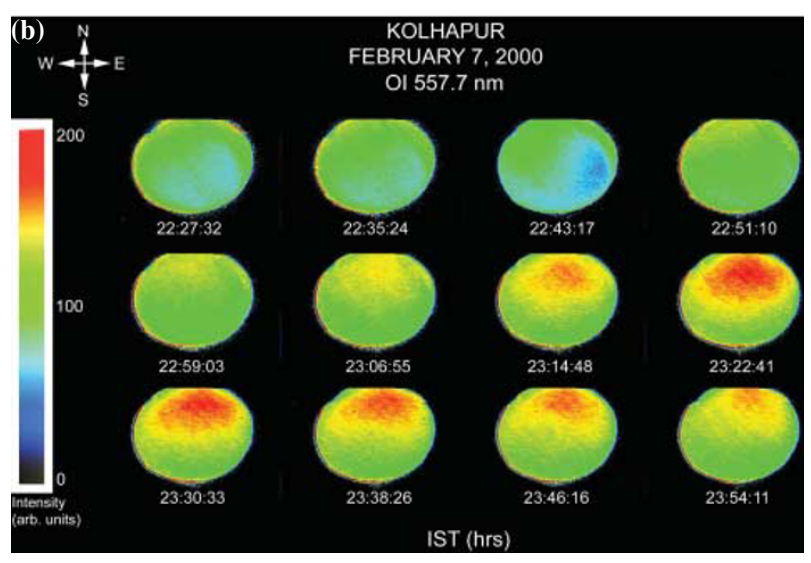

Fig. 4(b). Same as Fig. 4(a) but for intensity enhancement in OI $557.7 \mathrm{~nm}$.

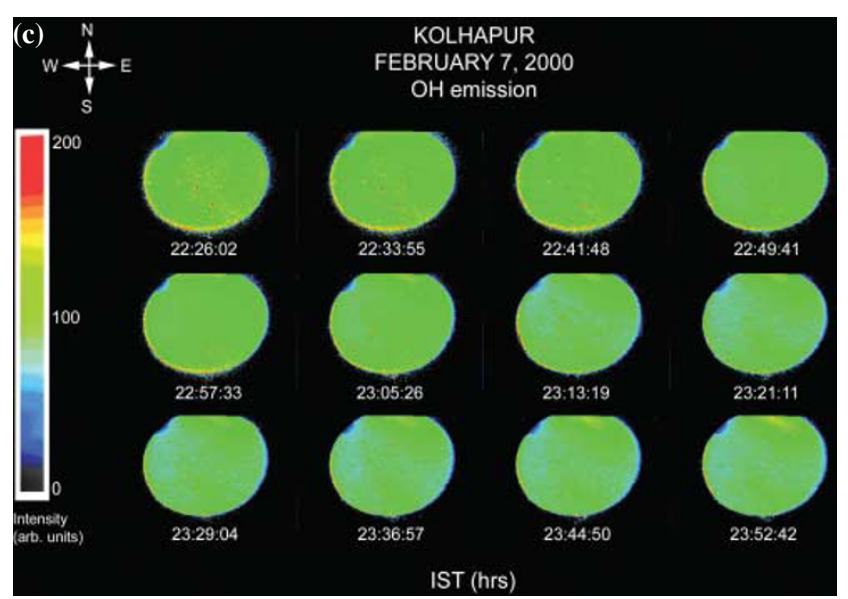

Fig. 4(c). All-sky images of hydroxyl (OH) emission showing no enhancement in intensity during the night (February 7, 2000).
February and November 1993 from Mt. Haleakala in Main Island, Hawai, Kiyama et al. (1996) reported the simultaneous measurement of the all-sky distribution of OI 630-nm airglow and hydroxyl $\mathrm{OH}(7,2)$ airglow. The all-sky intensity pattern of OI 630-nm was found to be modified during magnetic disturbance while the $\mathrm{OH}(7,2)$ band airglow varied independently of geomagnetic activity. This shows that in general the moderate geomagnetic activity had considerable effect on the evolution of OI 630-nm airglow in the low latitude regions while it had no effect on mesospheric emission lines such as $\mathrm{Na}(589.3-\mathrm{nm})$ and hydroxyl $(\mathrm{OH})$ airglow. The response of the MLT region to geomagnetic activity has generally been not very significant because the response can be nullified by various internal atmospheric processes such as stratospheric warming, seasonal transitions, atmospheric circulation of waves and local magnetic fluctuations (Balan et al., 2004 and references there in). However, the response has been found to be significant during intense magnetic storms $(K p>6)$ at altitudes above about $90 \mathrm{~km}$ (Johnson and Luhmann, 1988; Nozawa and Brekke, 1995; Larsen et al., 1997; Zhang and Shepherd, 2002; Salah and Goncharenko, 2001; Zhang et al., 2003). Singer et al. (1994), also through superposed epoch analysis, have investigated the influence of strong geomagnetic activity $(A p \geq 75)$ at $70-110 \mathrm{~km}$ altitudes using up to 10 years of data from 8 mid-latitude and high-latitude stations in the northern hemisphere. Using photometric data of Mt.Abu station $\left(24.65^{\circ} \mathrm{N}, 72.78^{\circ} \mathrm{E}\right)$ situated in the anomaly region, Kulkarni (1974) reported that on the day of magnetic storm $(\Delta H \geq 195 \mathrm{nT}) \mathrm{OH}(7,2)$ intensity was enhanced compared to the previous and following night.

The geomagnetic field data $(\mathrm{H}$ and $\mathrm{D})$ discussed in the report was obtained from a nearby station, Alibag $\left(18.63^{\circ} \mathrm{N}\right.$, $72.87^{\circ} \mathrm{E}$ ). The upper panels in Figs. 5(a) and 5(b) show the variation of geomagnetic field components (H and D) as a function of local time (IST). It is noticed that a geomagnetic storm (Sudden Commencement (SC) type) was in progress commencing at 21:12 IST on the night of February 5, 2000. The storm lasted up to the morning hours of February 8, 2000. The information on the magnetic activity during the nights has also been provided in Figs. 5 (a) and 5(b) by hourly Dst and three hourly Kp values of magnetic activity indices. On the night of February 7, 2000, the value of $\mathrm{Kp}$ index ranged from $4_{0}$ to $5_{-}$. In order to understand the ionospheric condition during the period of observation, we investigate the ionospheric data from a nearby station. Figures 5(a) and 5(b) also show the time variation of the ionospheric parameters, h'F $(\mathrm{km})$, the virtual height of the F-layer and square of the critical frequency of the F-layer (foF2) ${ }^{2}$ (proportional to $\mathrm{N}_{\max }$, the peak electron density of the ionospheric F-layer) at 15 minutes interval as a function of IST at Visakhapatnam, a station, situated at the same latitude as of Kolhapur for Feb 4-8, 2000. Compared to the night of February 4-5 (quiet day), there was an enhancement in electron density on each night at the station, the maximum enhancement took place around 22:30 to 23:30 IST on the night of February 7 (Fig. 5(b)). Comparing the period we find that there was also clear enhancement in OI $630-n m$ intensity around this hour. If the electron density enhancement is confined at an altitude range near the air- 
(a)

February $04-05,2000$ February $05-06,2000$
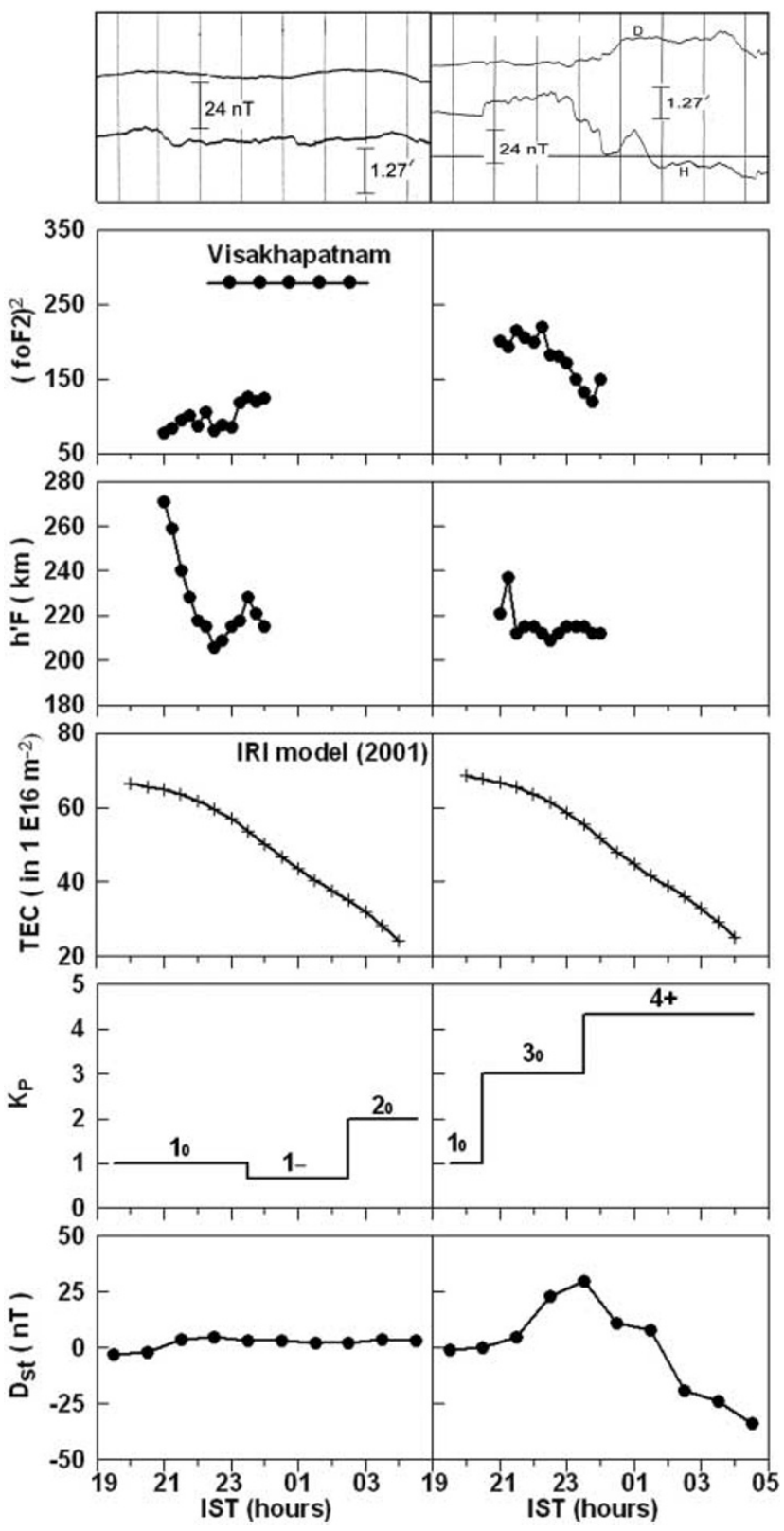

Fig. 5(a). The time variations of the (foF2) $)^{2}$ and h'F observed at Visakhapatnam on February 4-5 and 5-6, 2000. Also, plotted are the variations in Kp, Dst, TEC (computed from IRI2001 model) and magnetograms(horizontal component of magnetic field $(\mathrm{H})$, declination $(\mathrm{D})$ at Alibag $\left(18.63^{\circ} \mathrm{N}, 72.87^{\circ} \mathrm{E}\right)$.

glow layer, the enhancement may be seen in the $(\mathrm{foF} 2)^{2}$ variation, which is proportional to $N_{\max }$. The (foF2) $)^{2}$ variation on the night of February 6 shows inverse relation ship with h'F variation at the station. The virtual height (h'F) variations at the ionospheric sounding station, Visakhapatnem show large decrease in F-region height variations between 22:30 to 23:30 IST on the night (February 7). We also provide the Total Electron Content (TEC) values computed from integrating the electron density values from $60 \mathrm{~km}$ to $2000 \mathrm{~km}$ at the station, Kolhapur using IRI 2001 model under similar geophysical condition shown in one of the panels in the figures. TEC values computed show a general de- (b)

February $06-07,2000$ February $07-08,2000$
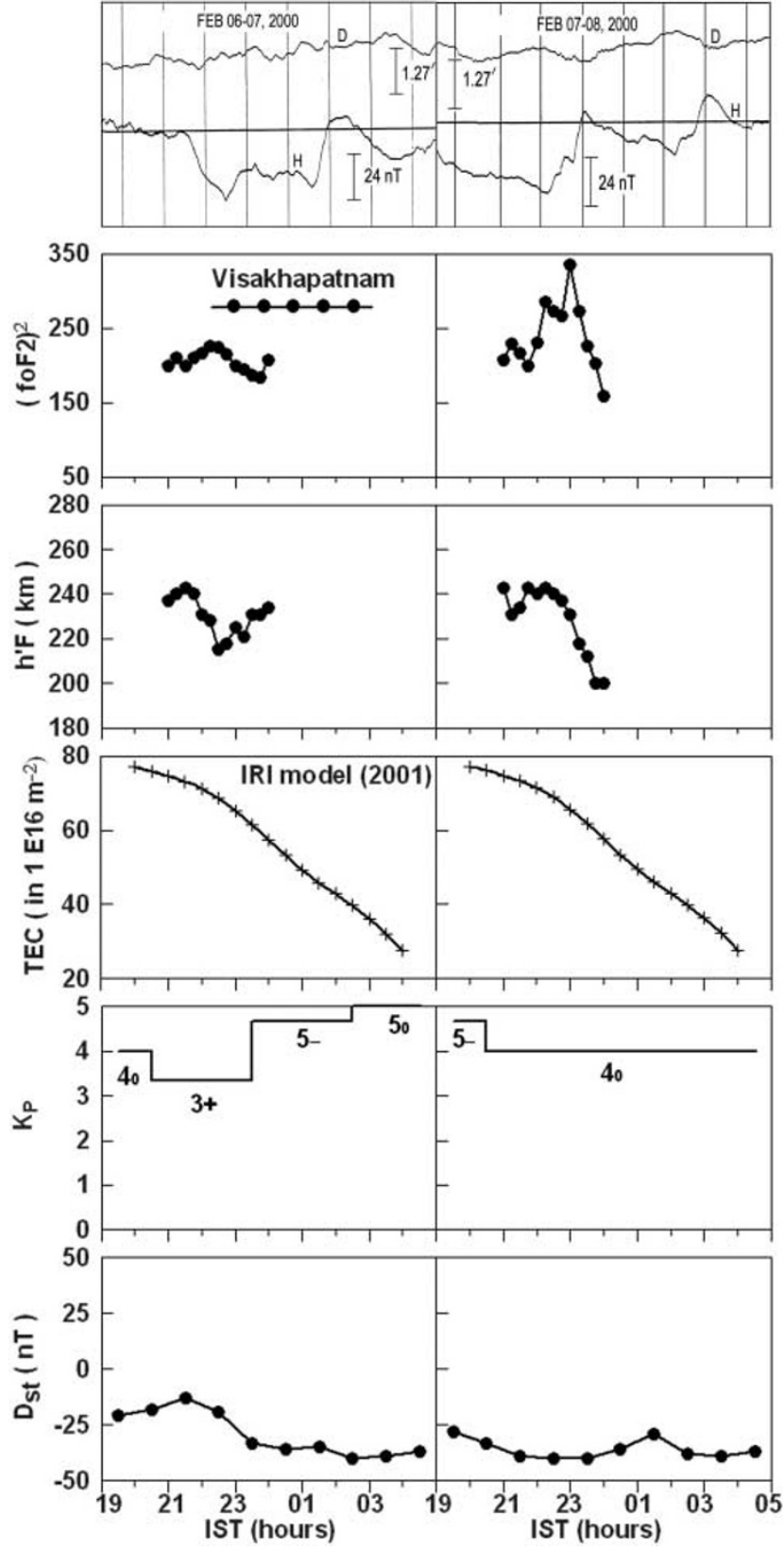

Fig. 5(b). Same as Fig. 5(a), but for February 6-7 and 7-8, 2000

crease in their values during the night, the model does not reflect the localized features of the enhancement of electron density during the period of the storm.

The photometric observations were also made with a set of filter-tilting photometers; the details of the instruments were given in Mukherjee and Dyson (1992). The tiltingfilter photometer has a one degree field of view (overall) giving a cross section of about $5 \mathrm{~km}$ diameter in the Fregion height $(250 \mathrm{~km})$ when looking at zenith. The airglow intensity is determined from the two positions of the filters, which give the difference of the background with signal and background only. The interference filters when kept at $23^{\circ} \mathrm{C}$ has a pass band centered at about $630 \mathrm{~nm}$ for normally incident light with pass band of $1 \mathrm{~nm}$ with $60 \%$ transparency. In Fig. 6 we plot the photometric intensity variation of OI 


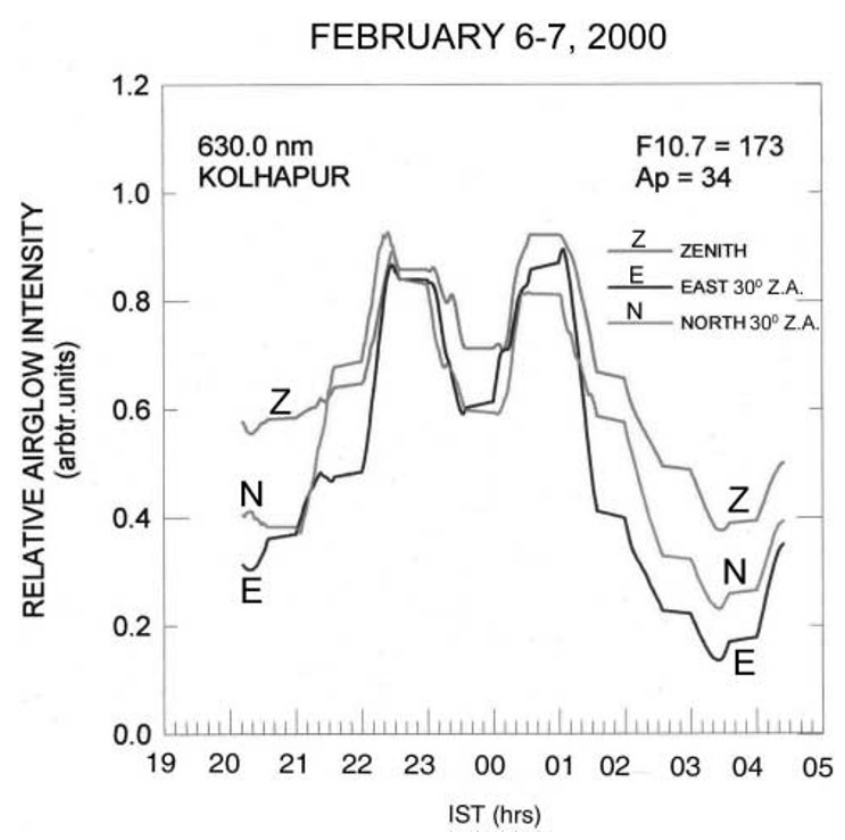

Fig. 6. Plot shows the OI $630-\mathrm{nm}$ intensity variation by three photometers on the night of February 6, 2000.

630-nm emission during the night of February 6-7, which was a magnetically disturbed night $(A p=34)$. There are two peaks in intensity occurring around 22:30 and 01:00 IST respectively. It is interesting to observe that the three photometers show the peaks in intensity almost around the same time.

With a view to study the small scale irregularities within the bubbles, VHF scintillations at $250.5 \mathrm{MHz}$ from FLEETSAT geostationary satellite were also monitored at Kolhapur during February 5-7, 2000. It was observed as shown in Fig. 7 that almost on everyday scintillations were recorded. However, on the night of February 7, the scintillations became weaker and the period of scintillation activity was also reduced. These results match well with the period of observation of ionospheric plasma bubbles at the station.

In order to check the behavior of the ionosphere at mid latitude stations we also plot in Fig. 8 the vertical TEC fluctuations at four mid-latitude stations in Japan during 4-8 February as a function of UT with a time interval of 15 minutes (Otsuka, private communication). The Total Electron Content (TEC) was measured continuously from the carrier phase delays ( $L=L 1-L 2)$ of two GPS signals $(L 1=1575.42 \mathrm{MHz}$ and $L 2=1227.60 \mathrm{MHz})$ in the ionosphere by using more than 1000 receivers of the Gobal Positioning Satellites (GPS) in Japan by the Geographical Survey Institute, Japan. The TEC variations are mapped on the geographical coordinates at an altitude of $250 \mathrm{~km}$ along the line of sight of between the ground receiver and the GPS satellites (altitude $=20,000 \mathrm{~km}$ ). The peaks observed around 3 UT on all the days are due to TEC enhancement during local noon hours at the stations. The amplitude level of TEC decreases during the first 24 hour of the storm (February 5) at all the stations with respect to quiet day (February 4, 2000); subsequently it gets enhanced each day reaching maximum value on February 7 . It was noted

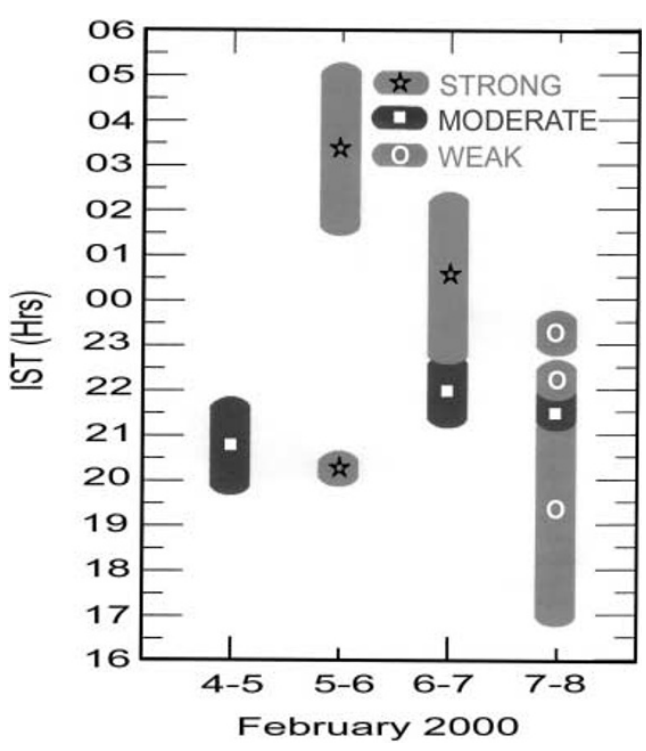

Fig. 7. Plot showing the strengths of the VHF scintillation activity during the period February 4-7, 2000 observed at Kolhapur.

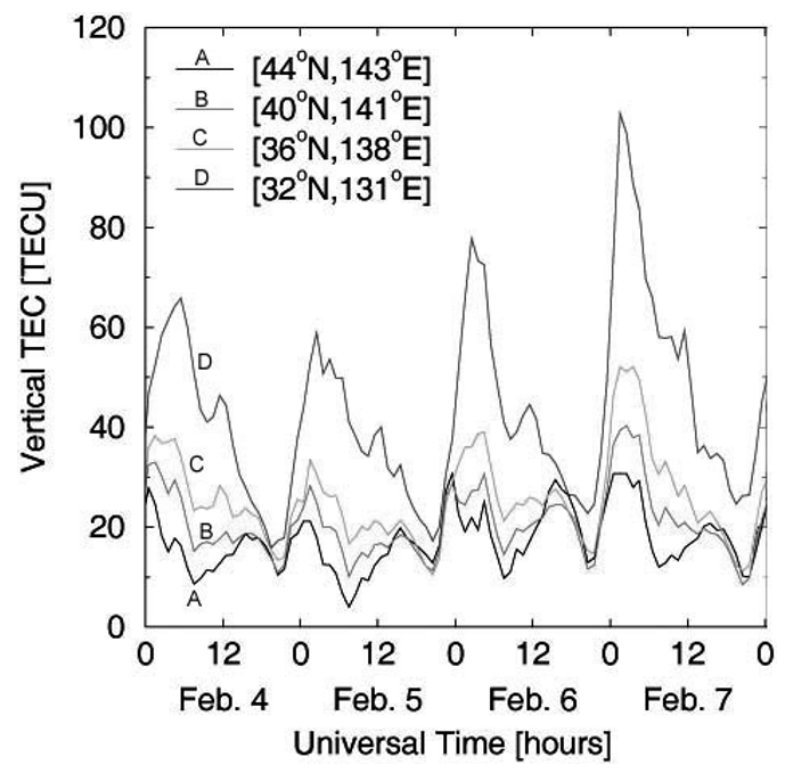

Fig. 8. Temporal variation of vertical TEC at four locations in Japan during February 4-7, 2000 showing noontime enhancement in TEC at three stations up to $40^{\circ} \mathrm{N}$ latitude on February 7 . The geographic latitude and longitude of the midlatitude stations are shown in the figure.

that the stations situated in lower and higher latitude regions showed higher and lower noontime TEC values. The TEC values around local noontime were enhanced at the stations up to $40^{\circ} \mathrm{N}$ latitude on February 7 compared to other days and the effect was more pronounced at the station $\left(32^{\circ} \mathrm{N}\right.$, $131^{\circ} \mathrm{E}$ ) closer to low latitude region. The peaks in TEC parameter coincided with the time ( 3 UT) of minimum in Dst index $(-44 \mathrm{nT})$ on February 7 . They may be correlated with a time varying electric field, which may penetrate to low latitudes (Yamamoto et al., 2000). The eastward or westward magnetospheric electric field causes an upward or downward vertical $E \times B$ plasma drifts, respectively. The $E \times B$ drift lifts the equatorial plasma on the dayside (due to positive electric field), which leads to increase in TEC. Since 
the 24 hour average of the vertical drift velocity must be equal to zero for the ionosphere, the upward drift by day time must be balanced by downward drift by night time. As a result the ionospheric plasma is pushed down on the night side causing depletion in TEC. Also, there was no enhancement in TEC around the local time (14-16 UT) at four mid latitude stations when the severe effect of the magnetic storm in airglow enhancement was felt at other low latitude Indian longitude regions. It should be noted that the TEC variations originate more from the F-layer peak height whereas the OI 630-nm variations correspond to about one scale height $(\sim 50 \mathrm{~km})$ below the $\mathrm{F}$ layer peak. Even the all-sky images in OI $630 \mathrm{~nm}$ from Shigaraki Observatory, Japan did not show any depletion or enhancement in intensity around the same time (Shiokawa, private communication). This confirms that the OI 630-nm airglow enhancement was confined to the low latitude regions during the period of maximum magnetic disturbance.

\section{Summary and Discussions}

In this paper the characteristics and dynamics of various nightglow emissions from a low latitude station, Kolhapur in India have been studied using a cluster of observation facilities (both radio and optical) during the period of a geomagnetic storm, 5-7 February 2000. The principal important features of these observations are summarized below:

1. All-sky imaging observations at Kolhapur show multiple depletions in OI $630 \mathrm{~nm}$ images on the night of February 5 and 6, 2000. The depletions are found to have zonal widths (east-west) varying with degree of depletions. This could be due to the growth phase of the development of the depletions or bubbles. The well-developed irregularities were having large amplitudes and the onset time irregularities were having smaller amplitudes or depths. A reversal of the normal nighttime downward drift of the F-layer to the upward direction is required to generate these irregularities (Aarons, 1991). At night zonal westward electric field produce a downward vertical drift. The effect, however, of the ring current in the midnight and post-midnight period when the layer height is normally decreasing and the electric field is westward, is to create for short time an eastward electric field which raises the height of the layer for shorter period of time, the layer height then falls after creating these irregularities. For the growth of these irregulatrities under magnetically disturbed condition a reversal of the normal nighttime downward drift of the F-layer to upward direction is required. The bubbles or depletions were not observed on the night of February 7, 2002. It is generally recognized that the height of the equatorial $F$ layer in the sunset time period is an important parameter controlling the generation of spread-F irregularities (depletions). The disturbance dynamo electric field and disturbance zonal wind produced by auroral activity could be responsible for the inhibition of the sunset enhancement of the electric field thereby reducing the height of the F layer. The gradient of electron density before the storm as well as changes in the gradient produced during the storm could also be the deciding factor in the generation of ionospheric plasma irregularities (Sahai et al., 1993).

2. There was an intense enhancement in OI 630-nm emis- sion intensity on the night of February 6 and 7 during the period of geomagnetic disturbance. The enhancements in airglow intensity were of the same order on two nights. Hourly Dst values were more or less comparable on the two nights as shown in Fig. 5(b). Tinsley et al. (1986) have pointed out that the intensity variations at low latitude stations are closely related to the magnetic signatures of the storm-time current system and the brightest emissions occur when Dst is large and specifically when positive horizontal magnetic field, $\mathrm{H}$ excursions take place. This is also evident here from the $\mathrm{H}$-field variations shown at low latitude station, Alibag $\left(18.63^{\circ} \mathrm{N}, 72.87^{\circ} \mathrm{E}\right)$ between $22: 30$ to 23:30 IST on February 7 (Fig. 5(b)). At the same time, electron density parameter $\left((\mathrm{foF} 2)^{2}\right)$ at Visakhapatnam reached its maximum value. Rishbeth et al. (1985) reported that in general, the equatorial anomaly is less developed during the storm periods. However, there are cases when the enhancements are strongly manifested in the crest region and the critical frequency in the equatorial trough is reduced compared to quiet days. Takahashi et al. (1987) have reported ionization enhancements at low latitudes during magnetic disturbed conditions. They showed that these enhancements were having an equatorial anomaly like structure having a minimum at the dip equator. Fesen et al. (1989) reported the prominent enhancements of F-region critical frequency in the ionization crest region during disturbed days.

The all-sky pattern of OI 630-nm and 557.7-nm airglow was found to be modified during the recovery phase of the storm while the hydroxyl $(\mathrm{OH})$ and $\mathrm{Na}(589.3-\mathrm{nm})$ airglow remained unaffected. The low latitude ionospheric data showed marked changes in foF 2 values during this period. It is seen that OI 630-nm enhancement was confined to low latitude region only and in the mid latitude region, the electron density parameter, TEC, did not show any enhancement or decrease at night. As OI 557.7-nm mesospheric emission receives a small contribution (about 20\%) from F-region airglow (Fagundes et al., 1995), if OI 630$\mathrm{nm}$ intensity is enhanced during magnetic disturbance, OI 557.7-nm contribution also gets modified proportionately. It is well understood that ground-based observations of OI 557.7-nm emission line receives two contributions to the integrated intensity emanating from two layers (from mesospheric E-region $(90-100 \mathrm{Km})$ and the thermospheric Fregion heights $(250-300 \mathrm{~km})$. When OI 630-nm emission is very intense, F layer component of OI 557.7-nm becomes very much stronger and can dominate the $96 \mathrm{~km}$ component significantly. Such abnormal enhancement in OI 630$\mathrm{nm}$ during the night could be explained by the mechanism of the penetration of high latitude electric field to low latitude equatorial regions of the ionosphere, which in turn could reduce the h'F layer and increase in (foF2) at low latitude regions. In general, a good correlation (c.c. $=0.8$ to 0.9 ) has been found between the measured atomic oxygen airglow at Kolhapur, India and F-region peak electron densities during quiet period. But for intense magnetic disturbances, the OI 630-nm fluctuations are mainly controlled by sharp changes in height variations of the h'F layer (Mukherjee et al., 2000). Also, the ground-based magnetic signature of particle precipitation from the ring current to low latitude regions during the recovery phase of a storm has been 
inferred from photometric OI 630-nm nightglow at Kolhapur in India. A large intensity increase of about seven times in OI 630-nm emission was observed at around 02:15 IST on December 23, 1995 at the time of high Dst or Kp index during the night (Mukherjee, 1999). The maximum optical emission occurred simultaneously with the maximum positive (north ward) excursions in the $\mathrm{H}$ trace of low latitude magnetograms associated with negative $\mathrm{H}$ excursions at high latitude observatories.

3. The ionosonde observations from low latitude station, Visakhapatnam showed the enhancement in electron density $\left(\sim(\text { foF } 2)^{2}\right)$ on the nights of February 5, 6 and 7 compared to February 4 (quiet day). The discrepancy in airglow enhancement and electron density during the nights, if any, may be due to height difference between the airglow producing layer and F-layer density peak. Also, the longitudinal variation of electron density at Visakhapatnam and Kolhapur at a given time may contribute to the observed difference.

4. The GPS-TEC observations at Japanese stations situated up to $40^{\circ} \mathrm{N}$ latitude showed amplitude enhancements around local noontime maximizing on February 7 . The effect was more pronounced at the station situated closer to low latitude region. The TEC enhancements may be caused by upward electron motion (fountain) in the low latitude region due to penetration of eastward electric field associated with the storm time substorms. However, the enhancement in TEC at the stations was not seen on February 7, 2000 around local midnight hours.

The classical picture of an ionospheric storm at low, mid latitude and high latitude region has been explained by Obyashi (1964) and Rajaram and Rastogi (1978). They found both positive and negative effects of the geomagnetic storm at mid and high latitude regions, only positive phases seem to appear at low latitude regions. This could be due to the effect of the negative phases of the storm dominant in the midlatitude region; only the positive effects were seen at low latitudes. This is primarily due to atmospheric effects that create $[\mathrm{O}] /\left[\mathrm{N}_{2}\right]$ enhancements at low latitudes, while $[\mathrm{O}] /\left[\mathrm{N}_{2}\right]$ decreases account for the dominant negative phase effects of the storm at a more poleward location (Mendillo et al., 2000). This phenomenon is related to the Joule heating in the region of the auroral oval which induces decrease in the ratio $[\mathrm{O}] /\left[\mathrm{N}_{2}\right]$ and correspondingly a decrease in electron density and foF 2 in the $\mathrm{F} 2$ region. The storm induced disturbance electric fields could account for the major responses: a direct penetration of magnetospheric electric field (often referred to as penetration electric fields) associated with substorm (asymmetric ring current) development/decay processes can occur in the low latitude equatorial regions and can produce lowering of the F-region of the ionosphere and subsequent enhancement in OI 630-nm emission due to dynamo field modifications. The direction of electric field is important. Also, the disturbance dynamo electric fields produced by changes in the thermospheric circulation originating from the energy deposition in high latitudes can produce heating in low latitude ionosphere with time delays of few hours (Sobral et al., 1997). Shiokawa et al. (2002) observed intense airglow band in Southern Okinawa in Japan during the period of a geomagnetic storm on
August 6, 2000 slowly moving with a velocity of $\sim 40 \mathrm{~m} / \mathrm{s}$ towards south. This band enhancement seems to correspond to the equatorial anomaly of the ionosphere.

Acknowledgments. The all-sky imaging system has been developed with the collaboration of Prof. M. Mendillo and his group at Boston University, Boston, and USA. The author is grateful to Prof. M. Mendillo for his continued interest in the project. Department of Science and Technology (DST), Government of India, New Delhi, fund the research in upper atmospheric science in IIG. The author is grateful to Dr. K. Niranjan, Andhra University, Visakhapatnam for providing the ionosonde data of Visakhapatnam. Station. The author is grateful to Dr. Y. Otsuka of STEL, Nagoya University, Nagoya for providing TEC plot of four Japanese stations. The theoretical computation of TEC values was done using IRI 2001 model parameters available at NSSDC Model web page. The nightglow observations at Kolhapur were carried out under collaborative research program between IIG, Navi Mumbai and Shivaji University, Kolhapur. Technical support received from Mr. P. T. Patil and Mr. S. H. Mahajan in Airglow work is gratefully acknowledged.

\section{References}

Aarons, J., The role of the ring current in the generation or inhibition of equatorial F layer irregularities during magnetic storms, Radio Sci., 26(4), 1131-1149, 1991.

Anderson, D. N. and M. Mendillo, Ionospheric conditions affecting the evolution of equatorial plasma depletions, Geophys. Res. Lett., 10, 541544, 1983.

Balan, N. et al., Simultaneous mesosphere/lower thermosphere and thermospheric F region observations during geomagnetic storms, J. Geophys. Res., 109, 120, 2004.

Barbier, D., Airglow and earth storm, J. Phys. Soc. Japan Supl., A-1, 255262, 1962.

Baumgardner, J. and S. Karandanis, CCD system using video graphics controller, Electronic Imaging, 3, 28-31, 1984.

Danilov, A. D. and L. D. Morozova, Ionospheric storms in the F2 region, Morphology and Physics (Review), Geomag. Aeron., 25, 593-604, 1985.

Fagundes, P. R., Y. Sahai, and H. Takahashi, Investigations of OI 557.7 $\mathrm{nm}$ and $630 \mathrm{~nm}$ nightglow intensity ratios during the occurrence of equatorial F-region plasma bubbles, J. Atmos. Terr. Phys., 57(8), 929932, 1995.

Fesen, C. G., G. Crowley, and R. G. Roble, Ionospheric effects at low latitudes during the March 22, 1989, Geomagnetic storm, J. Geophys. Res., 94, 5405-5417, 1989.

Johnson, R. M. and L. G. Luhmann, Cross correlation of high latitude upper mesosphere neutral winds with $\mathrm{AE}$ and $\mathrm{Kp}, J$. Geophys. Res., 93, 8625-8632, 1988.

Kane, R. P., Storm effects of ionospheric total electron content (TEC) at low latitudes, J. Geomag. Geoelectr., 33, 399-409, 1981.

Kiyama, Y., K. Kita, N. Iwagami, and T. Ogawa, Atomic oxygen 630 nm and $\mathrm{OH}$ Airglows at Mt. Haleakala, Hawaii in February and November 1993, J. Geomag. Geoelectr., 48, 337-341, 1996.

Kulkarni, P. V., Tropical Airglow, Ann. Geophys., 30, 105-115, 1974.

Larsen, M. F., A. B. Christensen, and C. D. Odom, Observations of unstable atmospheric shear layers in the lower E region in the post-mid-night auroral oval, Geophys. Res. Lett., 24, 1915-1918, 1997.

McClure, J. P., W. B. Hanson, and J. F. Hoffman, Plasma depletions and irregularities in the equatorial ionosphere, J. Geophys. Res., 82, 26502656, 1977.

Mendillo, M. and A. Tyler, Geometry of the depleted plasma regions in the equatorial ionosphere, J. Geophys. Res., 88, 5778-5882, 1983.

Mendillo, M., L. Bosheng, and J. Aarons, The application of GPS observations to equatorial aeronomy, Radio Sci., 35(3), 885-904, 2000.

Moore, J. G. and E. J. Weber, OI 6300 and OI 7774 A airglow measurements of equatorial plasma depletions, J. Atmos. Terr. Phys., 43, 851$858,1981$.

Mukherjee, G. K., Storm-associated variations of [OI] $630 \mathrm{~nm}$ emission from low latitudes, Terr. Atmos. Ocean. Sci., 10(1), 265-276, 1999.

Mukherjee, G. K., Studies of equatorial F-region plasma depletions and dynamics using multiple wavelength nightglow Imaging, J. Atmos. Sol. Terr. Phys. (UK), 65/3, 379-390, 2003. 
Mukherjee, G. K. and P. L. Dyson, A filter tilting photometer for nightglow measurement of 630.0-nm emission lines, Ind. J. Radio Space Phys., 21, 212-217, 1992.

Mukherjee, G. K., L. Carlo, S. H. Mahajan, and P. T. Patil, First results of all-sky imaging from India, Earth Planets Space, 50, 119-127, 1998.

Mukherjee, G. K., L. Carlo, and S. H. Mahajan, $630 \mathrm{~nm}$ nightglow observations from $17^{\circ} \mathrm{N}$ latitude, Earth Planets Space, 52(2), 105-110, 2000.

Nozawa, S. and A. Brekke, Studies of the E region neutral wind in the disturbed auroral ionosphere, J. Geophys. Res., 100, 14,717-14,734, 1995.

Obyashi, T., Research in Geophysics, edited by H. Odishaw, chap. 14, MIT Press, Cambridge, Mass., 1964.

Rajaram, G. and R. Rastogi, A synoptic study of the distributed ionosphere, during IGY and-IGC-(1) the Asian Zone, Ann. Geophys., 34, 31-36, 1978.

Rajaram, G., A. C. Das, and R. G. Rastogi, Ionospheric F-region disturbances and their possible mechanisms, Ann. Geophys., 27, 469-475, 1971.

Rishbeth, H., R. Gordon, D. Rees, and T. J. Fuller-Rowell, Modelling of thermospheric composition changes caused by a severe storm, Planet Space Sci., 33(1), 1283-1301, 1985.

Sahai, Y., A. Bittencourt, H. Takahashi, N. R. Teixera, J. H. A. Sobral, B. A. Tinsley, and R. P. Rohrbaugh, Multi spectral optical observations of ionospheric F-region storm effects at low latitude, Planet Space Sci., 36(4), 371-381, 1988.

Sahai, Y., A. Bittencourt, H. Takahashi, N. R. Teixera, B. A. Tinsley, and R. P. Rohrbaugh, Analysis of storm- time low latitude simultaneous ionospheric and nightglow emission measurements, J. Atmos. Terr. Phys., 52(9), 749-757, 1990 .

Sahai, Y., J. Aarons, M. Mendillo, H. Takahashi, M. A. Abdu, and E. R. da Paula, Studies of storm-time equatorial F-region irregularities, Proceedings of COSPAR Colloquium on Low-Latitude Ionospheric Physics held in Taipei, Taiwan, 9-12 November, 1993.

Sahai, Y., K. Shiokawa, Y. Otsuka, C. Ihara, T. Ogawa, K. Igarashi, S. Miyazaki, and A. Saito, Imaging observations of mid-latitude ionospheric disturbances during the geomagnetic storm on February 12, 2000, J. Geophys. Res., 106, 24,481-24,492, 2001.

Saito, B., Strong enhancements of airglow in low latitude regions during magnetic storms, Rep. Ionosph. Space Res. Japan, 27, 105-108, 1973.

Salah, J. E. and L. P. Goncharenko, Search for geomagnetic storm effects on lower thermospheric winds at mid latitudes, J. Atmos. Sol. Terr. Phys., 63, 951-963, 2001.

Shepherd, G. G., L. L. Cogger, and J. R. Burrows, Mid latitude Auroral and SAR Arcs observed from the ISIS-II Spacecraft during the August 1972 geomagnetic storm, J. Geophys. Res., 81(25), 4597-4602, 1976.

Shiokawa, K., Y. Otsuka, M. K. Ejiri, Y. Sahai, T. Kadota, C. Ihara, T. Ogawa, K. Igarashi, S. Miyazaki, and A. Saito, Imaging observations of the equatorward limit of mid latitude travelling ionospheric disturbances, Earth Planets Space, 54, 57-62, 2002.

Singer, W. et al., Geomagnetic influences upon tides-winds from MLT radars, J. Atmos. Terr. Phys., 56, 1301-1311, 1994.

Sobral, J. H. A., M. A. Abdu, W. D. González, B. T. Tsurutani, I. S. Batista, and A. L. Clua de Gonzalez, Effects of intense storms and substorms on the equatorial ionosphere/thermosphere system in the American sector from ground-based and satellite data, J. Geophys. Res., 102(A7), 14305-14313, 1997.

Takahashi, T., H. Oya, and S. Watanabe, Ionospheric disturbances induced by storm associated electric fields in the low latitude F-region, J. Geomag. Geoelectr., 39, 187-209, 1987.

Tinsley, B. A., Energetic neutral atom precipitation during magnetic storms: Optical emission, ionization and energy deposition at low and middle latitudes, J. Geophys. Res., 84, 1855-1864, 1979.

Tinsley, B. A., R. P. Rohrbaugh, H. Rassoul, Y. Sahai, N. R. Teixeira, and D. Slater, Low latitude aurora and storm time currents, J. Geophys. Res., 91, 11257-11269, 1986.

Tsunoda, T., On the spatial relationship of 1-m equatorial spread-F irregularities and plasma depletions, J. Geophys. Res., 85, 185-190, 1980.

Weber, E. J., J. Buchau, and J. G. Moore, Airborne studies of equatorial ionospheric irregularities, J. Geophys. Res., 85(A9), 4631-4641, 1980.

Woodman, R. F. and C. LaHoz, Radar observations of F region equatorial irregularities, J. Geophys. Res., 81, 5447-5466, 1976.

Yamamoto, A., Y. Ohta, T. Okuzawa, S. Taguchi, I. Tomizawa, and T. Shibata, Characteristics of TEC variations observed at Chofu for geomagnetic storms, Earth Planets Space, 52, 1073-1076, 2000.

Zhang, S. P. and G. G. Shepherd, Neutral winds and O $\left({ }^{1} \mathrm{~S}\right)$ emission rates in the lower thermosphere as measured with WINDII/UARS during the April 4-5th 1993 and February 1994 geomagnetic storms, J. Atmos. Sol. Terr. Phys., 64, 1201-1214, 2002.

Zhang, S. P., J. E. Salah, N. Mitchell, W. Singer, Y. Murayama, R. R. Clark, A. van Eyken, and J. Thayer, Response of the mesosphere wind at high latitudes to the April 2002 space storm, Geophys. Res. Lett., 30(23), 2225-2226, 2003.

G. K. Mukherjee (e-mail: gkm@iigs.iigm.res.in) 